Clinical Pediatrics,

1995, Vol. 34, No. 12, 642-647

\title{
Weaning Ages in a Sample of American Women Who Practice Extended Breastfeeding ${ }^{1}$
}

\author{
Muriel Sugarman, M.D. \\ Augusta Mental Health Institute, Augusta, Maine \\ Kathleen A. Kendall-Tackett, Ph.D., IBCLC \\ Family Research Laboratory, University of New Hampshire
}

\begin{abstract}
The present research examined age and method of weaning within a sample of 179 of women who practiced extended breastfeeding. The average age for weaning was between 2 years 6 months and 3 years 0 months, and ranged from 1 month to 7 years 4 months. Fourteen women had each weaned at least three children, and the youngest children were significantly older at the time of weaning than were their older siblings. Weaning was described as being "gradual" and "child-led" by the majority of women. A smaller, but substantial percentage of women cited reasons for weaning related to a subsequent pregnancy. Weaning ages for women who practice extended nursing were substantially older than were those of more typical North American mothers, and were similar to those in traditional cultures who have similar parenting practices.
\end{abstract}

\section{Extended Nursing and Weaning Ages in an Atypical Group of Breastfeeding Women}

In our culture, weaning from the breast typically occurs in the first two to four months (1-3), and women who nurse their children past infancy are an anomaly. Several recent studies (1-8) have found that women who practice extended nursing differ from the mainstream in other parenting practices as well. For example, women who nurse past infancy also tend to practice unrestricted breastfeeding, comfort nursing (using nursing as a means of both feeding and comforting infants), mother/child co-sleeping, and "babywearing." These practices are more similar to those of women in traditional cultures, such as the !Kung of the Kalahari desert, than they are to fellow North American women (9-10).

Initially, the practices of long-term nursing mothers were considered the province of radicals and fanatics, and of little interest to researchers. However, as the health benefits to both mother and child of extended nursing have become known (11-13), the issue of long-

1 This study was partially funded by a grant from the Boston Institute for the Development of Infants and Parents. The authors wish to thank Barbara Popper, M.Ed., Elizabeth Hormann, M.A.T., and Marsha Salett for their help with data collection and questionnaire development, and Edward Frongillo, Ph.D. for his feedback with regard to data analysis. 
term nursing is receiving serious scholarly attention. For example, the health benefits to both mother and baby of extended nursing were a topic of several presentations at the 1992 meetings of the American Association for the Advancement of Science (12). More recently (13), researchers have demonstrated that extended breastfeeding was related to a $30 \%$ reduction of risk for premenopausal breast cancer. The health benefits of extended nursing are impressive enough for the World Health Organization's Innocenti Declaration (14) to recommend breastfeeding for up to two years and beyond for infants worldwide.

While many of the practices of long-term breastfeeding women have been documented by previous research. The previous studies on this topic all had ceased collecting data before the children had weaned. Therefore, we do not know the range of weaning ages that occur in this atypical breastfeeding population. The goal of the present study is to examining weaning ages and practices in a sample of long-term breastfeeding women.

\section{Method}

\section{Study Population}

One hundred seventy nine women participated in this study. The women were recruited for participation in the study from La Leche League Area Conferences for parents, LLL leaders, and Lactation Consultants nationwide between 1989 and 1991. The survey forms were placed at the conference registration tables with a cover letter describing the purpose of the study and asking mothers if they would participate. In order to be eligible to complete the questionnaire, mothers had to have nursed at least one infant past the age of six months. Mothers could return the completed questionnaire form at the conference table or mail it to the address on the cover sheet. Four hundred questionnaires were distributed and 179 were returned for a completion rate of $45 \%$. Because these questionnaires were distributed at conferences (and we did not have the names of all of the women who picked up questionnaires), we were unable to send follow-up reminders to women who did not return questionnaires.

\section{Sampling Frame}

Women who nurse long-term are often reluctant to reveal this information, even to caregivers (15). Because of this secretiveness, it is difficult to identify the full sampling frame ahead of time. Therefore, a technique known as purposive sampling (16) was employed, with the target population being long-term breastfeeding women. As Suen and Ary describe (16), the representativeness of a purposive sample can be inferred by other sources of information, such as examining the samples of previous research on the population of interest, and comparing the present sample on key demographic variables. The demographic variables chosen for the present research were age at first birth and education level. 
All but one of the previous studies on long-term nursing have used samples from La Leche League (1-8). Samples were recruited from local groups (1-6) or advertisements in Leaven. the magazine for La Leche League leaders (7). The most recent study (8) was not conducted with League mothers, but was a prospective study drawn from the wider community. All of these studies described a similar population, i.e. women who were older at their first birth (typically ranging from 27 to 29.9 years), and having a higher level of education (50 to $62 \%$ was the range of college graduates in these samples) than women who did not nurse long-term. Interestingly, the non-League mothers in the one study (8) had the highest mean age at their first birth ( $M=29.9$ years). The mothers in the present sample were very similar on both age at first birth and education level, and were therefore thought to be an adequate representation of our target population.

\section{Instrument}

A closed-ended self-administered 96-item questionnaire was used. The closed-ended response categories were developed from a study conducted in 1974 (7). In the current version of the questionnaire, topics included were women's reasons for continuing to breastfeed past certain ages; their social, emotional and physical experiences associated with nursing; and demographic characteristics of the women, their partners, and their children. Women were asked for the ages of weaning for their three youngest children. For each of these children, the women were also asked how weaning occurred (e.g., suddenly, gradually, child-led, etc...). Finally, women were asked about their thoughts about how weaning should occur, and whether they had had any thoughts about weaning the child or children they were currently nursing (154 women were currently nursing a child, and 21 were simultaneously nursing more than one child).

\section{Analysis of Data}

Data were analyzed using McNemar's Test and Cochran's $Q$, which are both nonparametric techniques that allow for comparison of changes in distribution of dichotomous variables.

\section{Results}

\section{Sample Demographics}

The women's average age at the time of the survey was 34.4 years (range= 23-55), the average age of their partners was 37.2 years (range= 23-59), and the women's age at first birth was 27 (range= 17-40). Thirty-seven women were primiparous, 73 had two children, and 69 had three or more. Forty-three percent had graduated from college and an additional $25 \%$ had graduate degrees. Ninety-four percent were married at the time data were 
collected. We collected data on the weaning experiences of 134 women who had weaned a total of 211 children.

\section{Weaning Ages}

The age of weaning varied widely, ranging between 1 month and 7 years 4 months. The average age of weaning for children in the present study was 3 years 0 months for child A (the youngest), 2 years 9 months for child $\mathrm{B}$, and 2 years 6 months for child $\mathrm{C}$. The median ages were 2 years 11 months, 2 years 10 months, and 2 years 3 months for children $\mathrm{A}, \mathrm{B}$, and $\mathrm{C}$ respectively. These weaning ages are well over the typical age of weaning in the United States (i.e., two to four months), and are more consistent with ages of weaning in traditional cultures.

There appears to be an effect of birth order, with the youngest child nursing the longest. However, the ages presented above are for the entire sample of weaned children. Some women reported on more than one child and other women reported on only one child; both between- and within-groups data were included. In order to determine whether there was indeed a birth-order effect, data were partialled out for women who had weaned three children $(N=14)$, so that only within-subjects data were included. The mean age of weaning for these women is as follows: Child $\mathrm{A}=3$ years 7 months $(\mathrm{sd}=22.68$ months), Child $\mathrm{B}=2$ years 7 months ( $\mathrm{sd}=23.5$ months), Child $\mathrm{C}=2$ years 6 months ( $\mathrm{sd}=25.27$ months), $(F(2,26)=5.48, p<.01)$. This analysis of data from the 14 women who had weaned three (or more) children shows a trend similar to the data for the entire sample: women nursed their youngest child the longest period of time, perhaps because this child had not been supplanted by a sibling (15).

In order to determine if the age of weaning varied by the number of children a woman had weaned, cross-tabulations were calculated on number of children weaned by age of weaning ( $N=211$ children weaned), which is listed on Table 1. The highest percentage of women weaned their children at 37 months of age or later, and this did not vary whether the women had weaned one, two or three or more children $\left(\mathrm{X}^{2}(6)=8.42, p=.211\right)$. Eighty-three percent $(N=166)$ nursed past one year, $66 \%(N=133)$ nursed past 2 years, and $44 \%(N=88)$ nursed past 3 years of age. The reasons for weaning are listed on Table 2 . This table lists data for the entire sample and includes data from women reporting on one or more children. 


\section{Table 1}

\section{Ages of Weaning by the Number of Children Weaned}

\section{Number of Children Weaned Per Mother \\ $(N=211)$}

\begin{tabular}{c|l|l|l} 
& \multicolumn{1}{|c|}{$\mathbf{1}$} & \multicolumn{1}{|c}{$\mathbf{2}$} \\
\hline $\begin{array}{c}\text { Ages at Weaning In } \\
\text { Months }\end{array}$ & & & \\
\hline $\mathbf{0 - 1 2}$ & $11(15 \%)$ & $15(15 \%)$ & $9(21 \%)$ \\
\hline $\mathbf{1 3 - 2 4}$ & $12(17 \%)$ & $18(18 \%)$ & $11(26 \%)$ \\
\hline $\mathbf{2 5 - 3 6}$ & $15(21 \%)$ & $27(28 \%)$ & $3(7 \%)$ \\
\hline 37 or more & $33(46 \%)$ & $38(39 \%)$ & $19(45 \%)$ \\
\hline TOTALS & $72(100 \%)$ & $98(100 \%)$ & $42(100 \%)$
\end{tabular}

Numbers in each cell refer to the number of children who had weaned at each of the age groups for mothers who had weaned either one, two or three children.

\section{Reasons for Weaning}

The majority of women indicated that their reason for weaning was that it was "child-led." A smaller, but substantial, percentage of women cited reasons related to a subsequent pregnancy $(13 \%, 36 \%$, and $33 \%$ for children $\mathrm{A}, \mathrm{B}$, and $\mathrm{C}$ respectively). Other reasons included that the mother considered the child ready for weaning, or that an "illness" or "family circumstances" were related to weaning. Some for the reasons listed under "other" included not being able to seriously diet while nursing, and not being able to find attractive clothing that fit while nursing.

In describing how weaning was accomplished, the majority of women indicated that it was accomplished gradually. Over half of the women also described weaning as being child-led; only a small percentage of women described weaning as being sudden. A substantial percentage of women indicated that weaning was initiated by the mother, using a combination of talking to the child about weaning, substitution of a thumb or pacifier, deliberate introduction of a cup or other feeding mechanism $(28 \%, 46 \%, \& 45 \%$ for children $\mathrm{A}, \mathrm{B}$, and $\mathrm{C}$ respectively). 


\section{Table 2}

Reasons for Weaning and How Weaning was Accomplished for a woman's youngest three children (Child $A$ is the youngest)

$\begin{array}{lll}\text { Child A* } & \text { Child B } & \text { Child C } \\ N=25 & N=125 & N=69\end{array}$

Reasons for Weaning

(percentage of women selecting each reason)

Lack of Information

$5.3 \%$

$4.2 \%$

$8.7 \%$

Lack of Support or Opposition

2.6

4.2

8.7

Next Pregnancy Affected Taste or

Supply of milk

7.9

14.3

8.7

Next Pregnancy Affected Mother's

Motivation

Illness or separation from child

Child-led, happened naturally

Mother's decision that child was ready

Mother's decision based on Family

Circum.

Other

Number of Reasons (Mean)

$\begin{array}{lll}5.3 & 21.8 & 24.6 \\ 5.3 & 5.9 & 11.6 \\ 63.2 & 57.1 & 52.2 \\ 15.8 & 13.4 & 10.1\end{array}$

7.9

0

1.3
5.0

5.9

1.4
4.3

1.4

1.3

How Weaning was Accomplished (percentage of women selecting each method)

$\begin{array}{llll}\text { Sudden } & 12.8 \% & 7.6 & 8.8 \\ \text { Gradual } & 56.4 & 60.2 & 45.6 \\ \text { Child-led } & 53.3 & 56.7 & 54.1 \\ \text { Mother Deliberately weaned } & 2.6 & 11.0 & 13.2 \\ \text { Mother Encouraged by Talking } & 23.1 & 31.4 & 20.6 \\ \text { Substituted Thumb, pacifier } & 2.6 & 3.4 & 1.5 \\ \text { Other } & 1.7 & 1.8 & 1.7 \\ \text { Number of Reasons (Mean) } & 1.8 & 1.8 & 1.7\end{array}$


In order to determine whether reasons for weaning varied by birth order of the child, data were analyzed separately for women who had weaned more than one child. For women who had weaned at least three children $(N=14)$, data were analyzed by Cochran's $Q$ Test for each reason listed on Table 2. None of the within-subjects differences were significant, however. For women who had weaned two children $(N=44)$, data were analyzed by McNemar's Test for each of the reasons listed on Table 2. Again, none of these were significant. There does not appear to be a birth-order effect for reasons given for weaning.

The women who were currently nursing a child were asked about their thoughts about weaning. Of these women, $36 \%$ indicated that they had thought at some point about weaning the child they were currently nursing. The reasons for weaning or not weaning are found on Table 3.

\section{Table 3}

\section{Approaches to Weaning for Those Currently Nursing}

Reasons for Weaning or Not Weaning ("Have you thought about weaning this child?")

No, weaning should be child-led

No, enjoy the nursing relationship

Yes, for a specific reason

(pregnancy, returning to work)

Yes, child is ready/child is biting

Yes, due to social pressure

Yes, child is nursing too frequently

for age
$75.9 \%$

72.3

4.8

7.8

3.6

3.6

When asked about their approaches to weaning, $88 \%$ indicated that weaning should be childled, $11.4 \%$ indicated that they would cut down the number of nursing sessions, $31 \%$ indicated that they would substitute other forms of love, and $31 \%$ indicated that they would only nurse when the child wanted to (practicing "don't offer, don't refuse").

\section{Discussion}

The results of the present study indicate that for women who practice extended breastfeeding women, weaning occurs at a much later age than it does typically in our culture. The average age of weaning was between $21 / 2$ and 3 years of age, and was highest for the youngest child. The wide range of weaning was among one of the more interesting 
findings, particularly the high percentage of women whose babies wean after 37 months (see Table 1). This finding held true whether women had weaned 1, 2 or 3 children.

Age of weaning raises two important issues. First, from a theoretical standpoint, it is interesting to consider whether Western women practicing extended breastfeeding nurse their children until the late ages that their counterparts in traditional cultures do (for example, in the above-mentioned !Kung, weaning ages are, on average, between ages 2 and 3). This question is especially interesting when one considers the "social coercion for weaning" that previous research has linked to the early age of weaning in the U.S. (1-3). Does this social coercion lead to earlier ages of weaning for women practicing extended breastfeeding in our culture or do the ages of weaning resemble those for women in traditional cultures? In other words, once the process of extended nursing is in place, will it continue on its natural course, impervious to cultural influences, or will the culture influences shorten the time of nursing? Our data suggest that women who practice extended nursing and child-led weaning are likely to nurse well into toddlerhood. Our findings are also consistent with Lawrence's (17) clinical observation that true child-led weaning seldom takes place before age 4 , and they are consistent with the weaning ages found in traditional cultures such as the !Kung (10).

Second, many practitioners have never encountered long-term nursing in their practices because women who long-term nurse do so secretly (15). By being unaware of this practice, they may not even ask mothers if they are continuing to nurse, which as pediatricians Cable and Rothenberger have noted (4), could limit practitioners' access to important information. Simply knowing that extended nursing exists in our culture can be helpful to practitioners.

\section{Conclusions}

Extended nursing is so unusual in our culture that women may receive a great deal of criticism for continuing to nurse. While extended nursing is uncommon in our culture, it is not unusual from a global perspective, and is more in line with the recommendations of the World Health Organization than are the early weaning ages that are more typical among North American mothers. Upon encountering mothers who are nursing past infancy, it is important to bear in mind that the criticisms these mothers receive are based on cultural preference rather than scientific data. No empirical study to date has demonstrated that extended nursing is harmful, but a number of previously cited studies have found benefits. Therefore, practitioners can be confident in supporting mothers who choose to nurse their children into toddlerhood and beyond.

\section{References}

1. Morse JM, Harrison MJ. Social coercion for weaning. J Nurs Midwif. 1987; 32:205-210 
2. Wrigley EA, Hutchinson SA. Long-term breastfeeding: The secret bond. J Nurs Midwif. $1990 ; 35: 35-41$

3. Rogers CS, Morris S, Taper LJ. Weaning from the breast: Influences on maternal decisions. Ped Nurs. 1987; 13:341-345

4. Cable TA, Rothenberger LA. Breastfeeding behavioral patterns among La Leche League mothers: A descriptive study. Pediatrics. 1984; 73:830-835

5. Buckley KM. Beliefs and practices related to extended breastfeeding among La Leche League mothers. J Peri Educ. 1; 1992:45-53

6. Elias MF, Nicholson NA, Konner M. Two subcultures of maternal care in the United States. In DM Taub \& FA King (Eds.) Current perspectives in primate social dynamics. 1986:37-50

7. Reamer SB, Sugarman M. Breastfeeding beyond six months: Mothers' perceptions of the positive and negative consequences. J Trop Ped. 33;1987: 93-97

8. Hills-Bonczyk SG, Tromiczak KR, Avery MD, Potter S, Savik K, and Duckett LJ.

Women's experiences with breastfeeding longer than 12 months. Birth. 1994; 21:4: 206-212

9. Newton N, Newton M. Psychologic aspects of lactation. N Engl J Med. 1967; 277:11791188

10. Konner MJ. Maternal care, infant behavior and development among the !Kung. In RB Lee \& I DeVore Kalahari hunter-gatherers. Cambridge, MA: Harvard University Press; 1976:218-399

11. Goldman AS, Goldblum RM, \& Garza C. Immunologic components in human milk during the second year of lactation. Acta Paediatr Scand, 1983; 72: 461-462

12. Poole S. Darwin takes on mainstream medicine. J of NIH Res. 1993: 64-66

13. Newcomb BE, Storer MP, Longnecker et al. Lactation and a reduced risk of premenopausal breast cancer. N Engl J Med 1994; 33:81-87

14. UNICEF-WHO. Innocenti declaration: On the protection, promotion and support of breastfeeding. New York: UNICEF; 1990

15. Avery JL. Closet nursing: A symptom of intolerance and a forerunner of social change? Keeping Abreast J. 1977; July-Sept: 212-227 
16. Suen HK \& Ary D Analyzing quantitative behavioral observation data. Hillsdale, NJ: Lawrence Erlbaum: 1989

17. Lawrence RA. Breastfeeding: A guide for the medical profession. St. Louis, MO: CV Mosby; 1989 